\title{
Marcas espaciais da paisagem rural: as rugosidades de Cachoeira do Sul/RS
}

\author{
Space imprints of rural landscape: the roughness of Cachoeira do Sul/RS
}

\begin{abstract}
Lisane Regina Vidal Conceição Doutora em Geografia pela Universidade Federal de Santa Maria - UFSM, Professora da Rede Estadual de Educação do Estado do Rio Grande do Sul, Brasil

lisanevidal@gmail.com
\end{abstract}

Eduardo Schiavone Cardoso Professor Titular do Departamento de Geociências e do Programa de Pós-Graduação em Geografia da Universidade Federal de Santa Maria - UFSM, Brasil educard@smail.ufsm.br

\begin{abstract}
Resumo
A pesquisa objetivou identificar no espaço e tempo a constituição das rugosidades na paisagem rural do município de Cachoeira do Sul/RS. Para a realização da investigação, utilizaram-se os aportes metodológicos baseados no Materialismo Histórico, no método dialético e na abordagem qualitativa. As rugosidades são o que fica do passado como forma, paisagem, como espaço construído, possibilitam compreender o espaço como produto da ação humana, ao longo da sua história. Foram elencadas três tipologias de rugosidades no município: as rugosidades do Sistema de Circulação de Mercadorias e Pessoas (as pontes, viação férrea, porto, balsas, posto telefônico, posto de combustível e correio); as rugosidades do Sistema de Produção (as estâncias, fazendas, engenhos, charqueada, banheiro de imersão bovino e venda); e o Sistema de Interação Social (as casas antigas, escolas, igrejas, salão de baile, taperas e cemitérios familiares). As rugosidades devem ser entendidas como meios que possibilitam ressignificações e não como entraves ao desenvolvimento socioeconômico do lugar. A sua presença concreta valoriza o espaço e sua ressignificação possibilita aos grupos sociais do presente novas fontes de renda, de permanência no meio rural, contribuindo tanto para sua produção e reprodução como também para preservar do esquecimento e salvaguardar na memória as rugosidades.
\end{abstract}

Palavras-chave: Espaço-Tempo; Rugosidades; Paisagem; Espaço Rural.

\begin{abstract}
The research aimed to identify the space and time the Constitution of the roughness in the countryside of the municipality of Cachoeira do Sul/RS. For the realization of research, were used the methodological contributions based on historical materialism, dialectical method and qualitative approach. The roughness is what is passed as form, landscape, like space built, make it possible to understand the space as a product of human action, along with its story. Were listed three types of roughness in the municipality: the roughness of the System of Movement of Merchandise and People (bridges, railway road, port, ferries, telephone station, gas station and post office); the roughness of the Production system (offices, farms, plantations, the farm where salted and sliced beef is produced, immersion bath for cattle); and the Social Interaction System (old houses, schools, churches, ballroom, abandoned places and family cemeteries). The roughness must be understood as a means to enable resignifications and not as obstacles to the socio-economic development of the place. Its concrete presence enhances the space, and its resignification allows to the social groups new sources, of permanence in the rural areas, contributing to its production and reproduction as well as to preserve it from oblivion and safeguard in memory the roughness.
\end{abstract}

Keywords: Space-time; Roughness; Landscape; Rural Area. 


\section{INTRODUÇÃO}

Milton Santos, em sua vasta obra, menciona que o espaço esconde de nós pesquisadores as múltiplas relações que ali se estabelecem, uma vez que mostra apenas o visível, a forma e a paisagem, escondendo as múltiplas relações necessárias à forma criada.

As múltiplas inter-relações ao se materializarem no espaço formam as rugosidades. Este conceito foi desenvolvido por Santos (1978) no livro "Por uma Geografia Nova", no qual o autor menciona que rugosidade é o que fica do passado como forma, como paisagem, como espaço construído. Elas podem se transformar ou se adaptar a novos processos impostos pelas relações de poder estabelecidas nas inter-relações dos grupos sociais.

Para compreender como as rugosidades são produzidas no espaço rural é imprescindível entender que elas estão ligadas ao modelo de desenvolvimento adotado no país e como os grupos sociais, ali inseridos, reagem à inserção de novas tecnologias a eles impostas, contribuindo, assim, para a justaposição de técnicas, contraditórias entre si, mas necessárias à reprodução dos grupos sociais e da própria reprodução do sistema capitalista.

Para tanto, definiu-se como área de estudo o município de Cachoeira do Sul, quinto $\left(5^{\circ}\right)$ município criado no Estado do Rio Grande do Sul (Figura 1), caracterizado pela diversidade do espaço rural. Na margem direita do rio Jacuí, na sua porção sul, configura-se a influência da implantação das sesmarias, baseada na grande propriedade, produção de monoculturas e de pecuária para atender ao abastecimento externo, introduzido na paisagem rural no período colonial. $\mathrm{Na}$ margem esquerda do rio Jacuí, na sua porção norte, apresenta influência de um processo de colonização dirigida germânica, baseada na pequena propriedade e produção para o autoconsumo, implantada no período imperial como nova forma de produzir para garantir a necessidade de abastecimento interno, ocupação das fronteiras em litígio e introdução de etnias que promovessem o branqueamento da população, configurando-se dentro do processo de expansão das relações capitalistas em nível global.

Desta forma, objetiva-se identificar no espaço e tempo a constituição das rugosidades na paisagem rural do município de Cachoeira do Sul/RS. As rugosidades podem ser consideradas indicadores da transformação do espaço, pois sua materialização como trabalho morto é base para a sociedade determinar seu trabalho vivo, ou seja, compreendem restos de trabalho passado que ao permanecer no presente, ressignificado ou não, influenciam a reprodução atual. 


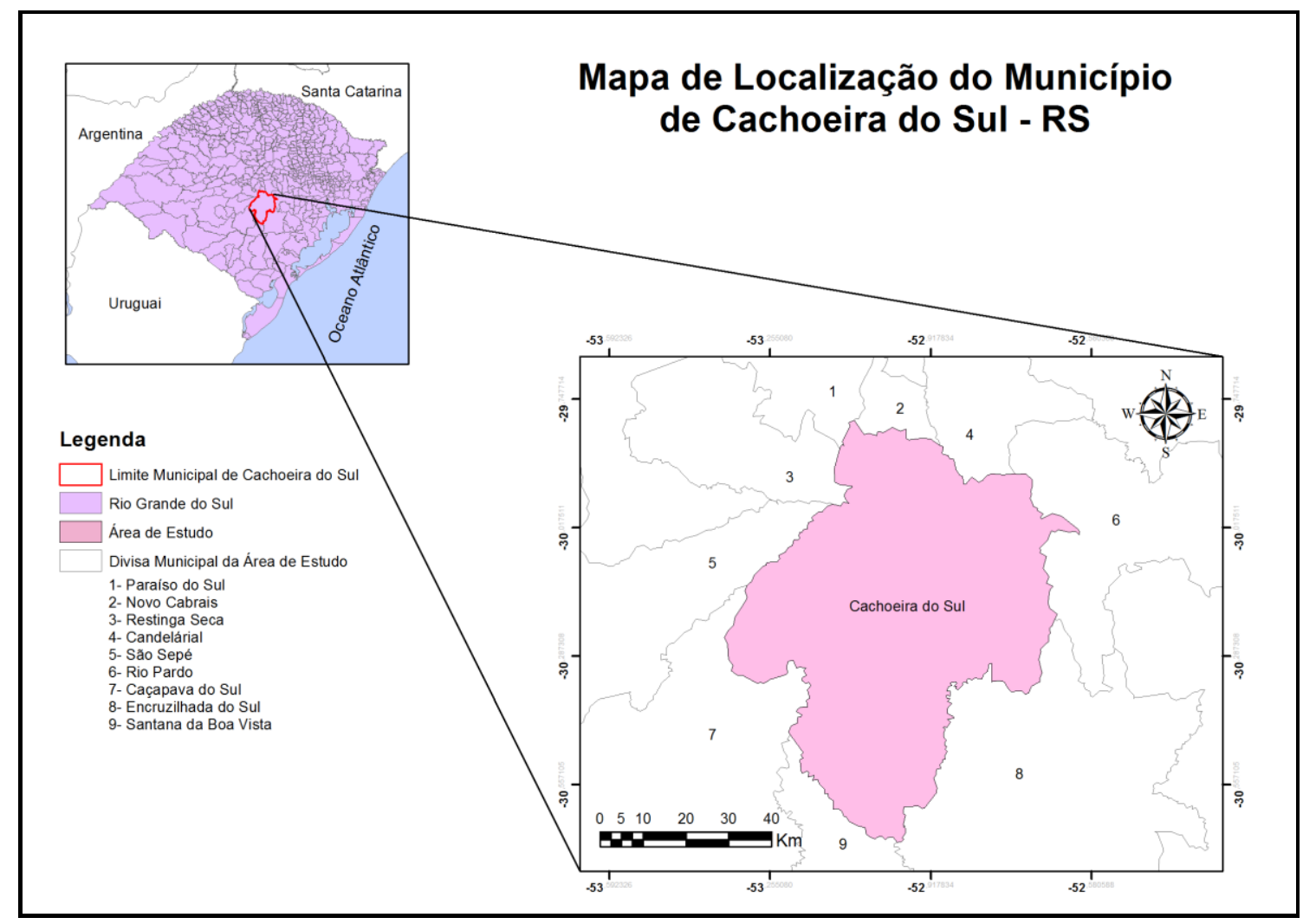

Figura 1 - Localização do Município de Cachoeira do Sul no estado do Rio Grande do Sul.

Fonte: Malha do Municipal IBGE (2010).

O estudo das rugosidades possibilita compreender as múltiplas inter-relações criadas pela sociedade concreta ao criar o espaço geográfico, se reproduzir e se repetir. As rugosidades permitem reflexões além da forma criada, possibilitam análises que desvendam os agenciamentos necessários emendados para o homem produzir seu espaço de vida, portanto, elas são marcas espaciais que permitem compreender como, por quem e para quem o espaço geográfico é criado. Sua materialização é o reflexo de relações de poder que movem e transformam o espaço. Portanto, entende-se que seu estudo é necessário para quem deseja compreender a complexidade da produção do espaço geográfico.

Para atingir o objetivo traçado a investigação fez uso do aporte teórico-metodológico contido na Teoria Social Crítica baseada na abordagem do Materialismo Histórico e no método Dialético. Fundamenta-se em uma abordagem qualitativa, cuja delimitação temporal e espacial do fenômeno estudado é dada pelo espaço rural e pela datação da rugosidade nesta espacialidade.

A investigação fez uso da pesquisa bibliográfica, pesquisa documental, pesquisa de campo através da aplicação de entrevistas e diário de campo, a fim de elaborar um inventário das rugosidades presentes na paisagem rural municipal. Para a sistematização das rugosidades fez-se uso de fotografias georreferenciadas para posterior espacialização e comprovação da existência das rugosidades no espaço rural, bem como o uso do Software Sistema de Informações Geográficas (ArcGis 9.3 e 10.2) para a confecção de mapas do município em estudo. 
Em direção ao cumprimento dos objetivos propostos, a elaboração do inventário das rugosidades da paisagem rural primou-se em caracterizá-las, situá-las no contexto histórico de sua criação, compreender a origem e o desenvolvimento das formas e funcionalidades criadas, bem como seu significado no presente. Portanto, a construção do inventário procurou evidenciar a importância das rugosidades na construção da espacialidade rural, na tentativa de torná-las objeto de preservação patrimonial e fontes de reprodução social aos grupos sociais locais.

$\mathrm{Na}$ tentativa de sistematizar e estruturar de forma didática o inventário foram elencadas três (3) tipologias: o Sistema de Circulação de Mercadorias e Pessoas; o Sistema de Produção e; o Sistema de Interação Social. Na espacialização das rugosidades optou-se por periodizá-las de acordo com o período histórico de sua materialização espacial, assim, elas foram agrupadas de 1801 a 1900 (século XIX) e de 1901 a 2000 (século XX), a fim de evidenciar as diferentes temporalidades materializadas e o contexto histórico e econômico de sua criação.

\section{ESPAÇO-TEMPO E AS RUGOSIDADES}

O espaço deve ser considerado como uma totalidade. Entretanto, sua análise exige a possibilidade de dividí-lo em partes, a qual ao seu término deve reconstituir o todo. Assim, Santos (2014) define os elementos do espaço: os homens, as firmas, as instituições, o meio ecológico e as infraestruturas. Os homens são os produtores do espaço, as firmas são responsáveis pela produção de bens, serviços e ideias, as instituições produzem normas, ordens e legitimações, o meio ecológico é o conjunto de complexos territoriais que constituem a base física do trabalho humano e, as infraestruturas é o trabalho humano materializado e geografizado. (SANTOS, 2014).

Para Santos (2014) o espaço deve ser analisado a partir das categorias forma, função, estrutura e processo. A forma é a o aspecto visível, o exterior de um objeto, seja ele considerado isolado ou através de um arranjo de objetos, formando um padrão espacial. A função requer uma tarefa, uma atividade ou papel a desempenhar pelo objeto criado, a forma. Não se pode separar a forma da função na análise espacial. Porém, é necessário ir além, ou seja, inserir a forma e função na estrutura social. Assim, a estrutura representa a natureza social e econômica de uma sociedade, em um dado momento histórico. Portanto, a estrutura é a matriz social onde as formas e as funções são criadas e justificadas. (SANTOS, 2014).

O processo é definido como uma ação que se realiza de modo continuo em função de um resultado qualquer, provocando tempo e mudança. Os processos acontecem no âmbito de uma estrutura social e econômica, ocasionado contradições internas das mesmas, ou seja, o processo é a estrutura em seu movimento de transformação (SANTOS, 2014). 
Corrêa (1986) indica que o objeto da geografia é a sociedade, o qual deve ser estuda através da organização espacial. Portanto, a organização espacial ao ser produto da própria produção humana em sua história de vida, é fruto do trabalho social e das relações e inter-relações das classes sociais. A sociedade concreta cria o espaço geográfico para se realizar e se reproduzir, para ela própria se repetir. E, para isso, cria formas duradouras que se cristalizam sobre a superfície terrestre, garantindo a reprodução e continuidade da sociedade.

Assim, as múltiplas inter-relações ao se materializarem no espaço formam as rugosidades, denominados por Santos (1986, p. 138):

As rugosidades são o espaço construído, o tempo histórico que se transformou em paisagem, incorporado ao espaço. As rugosidades nos fornecem, mesmo sem tradução imediata, restos de uma divisão de trabalho internacional, manifestada localmente por combinações particulares do capital, das técnicas e do trabalho utilizado. (SANTOS, 1986, p. 138).

As rugosidades designam as marcas do passado fixadas no espaço. A sua presença acaba condicionando o nosso cotidiano e, ao se projetar este raciocino no tempo, pode-se dizer que o presente condiciona o futuro. As formas espaciais presentes têm um importante papel para as sociedades futuras. (CORRÊA, 1986).

Assim, o espaço é um testemunho. Testemunha um momento de um modo de produção nas suas manifestações concretas, pela memória do espaço construído, das coisas fixas da paisagem criada. O espaço é uma forma durável que não se desfaz paralelamente as mudanças de processos, mas, ao contrário, faz com que alguns processos se adaptam as formas preexistentes e que outros criem novas formas para se inserir dentro delas. (SANTOS, 1986).

Santos (1986) destaca que os modos de produção se realizam através dos meios de produção, cuja longevidade somente é conhecida a posteriori, a qual pode durar vários momentos ou a duração total do modo de produção. Neste contexto, para compreender as rugosidades, deve-se ter clara a noção de temporalidade. Apreender a temporalidade é compreender o espaço como fruto de diversas divisões territoriais do trabalho ao longo da história da humanidade. A temporalidade possibilita a compreensão das diversas dimensões que compõem o espaço. Permite compreender quais atores e como estes construíram o espaço, possibilita também entender como as sociedades atuais se relacionam com o espaço já criado, herdado.

Desta forma, quando um novo modo de produção, um novo momento, substituiu outro, ele encontra formas preexistentes, as quais devem adaptar-se para determinar-se. Desta forma, o modo de produção presente deve adaptar o antigo a sua lógica de produção e, quando não o faz, o capital tende a abandonar este espaço, tornando-o um subespaço de acordo com sua lógica. Assim, em cada lugar, o tempo atual se defronta com o tempo passado, cristalizado em formas. E, assim, para o 
tempo atual, os restos do passado formam uma espécie de "escravidão das circunstâncias anteriores". (SANTOS, 2012).

As rugosidades se apresentam como formas isoladas ou como arranjos. É dessa forma que elas são uma parte desse espaço-fator. As rugosidades é o que fica do passado como forma, espaço construído, paisagem, o que resta do processo de supressão, acumulação, superposição, com que as coisas se substituem e acumulam em todos os lugares. (SANTOS, 2012).

Portanto, as rugosidades só são rugosidades a partir do presente. Os espaços preexistentes decorrem de uma divisão de trabalho antiga, passada, e só entra em desuso sob uma nova lógica de compreender este espaço, a qual se adapta ou o adapta, o transforma, cria ou recria novas funções a estas formas espaciais. Assim, Moraes e Costa (1984) enfatizam que as sociedades humanas para reproduzirem as condições de sua existência, estabelecem relações vitais com o seu espaço, cujo trabalho é o mediador universal dessa relação. Sendo o trabalho a fonte do valor, tal relação do ponto de vista marxista, é um processo de valorização.

A sociedade, em qualquer época ou lugar, na sua própria existência valoriza o espaço. Neste contexto, é importante salientar que a valorização do espaço possui movimento próprio, elementos específicos que a caracterizam e resultados histórico-concretos particulares. As formas criadas por uma sociedade revelam a estrutura econômica que ali domina, entretanto, esse processo possui uma realidade especifica em cada modo de produção, portanto, cada modo de produção possui seu modo particular de valorização. (MORAES; COSTA, 1984).

O processo de valorização do espaço deve ser explicado através das categorias valor e trabalho, pois a relação sociedade-espaço é uma relação valor-espaço, substantivada pelo trabalho humano. A apropriação dos recursos do espaço, a criação de formas humanizadas, a perenização (conservação) desses constructos, as modificações dos substratos naturais ou das obras humanas, representam a criação de valor. Cabe ressaltar que ao analisar o processo de valorização do espaço deve-se ter clara a distinção de valor do espaço e valor no espaço. (MORAES; COSTA, 1984).

O valor do espaço se expressa na qualidade, quantidade e variedade de recursos naturais disponíveis em uma porção do espaço terrestre, denotando a singularidade natural dos lugares, consistindo, assim, numa parcela de valor do espaço, seja como primeira ou segunda natureza. A segunda parcela de valor do espaço é obra principalmente do trabalho, à medida que o desenvolvimento das forças produtivas tende a criar formas mais duráveis sobre o espaço. Assim, Moraes e Costa (1984, p. 125) fazem referência às contribuições de Milton Santos:

Milton Santos, de forma brilhante, expõe a essência desse processo de produção do espaço. Para ele, os modos de produção criam formas espaciais que duram mais que os processos que as engendrou. Denomina a essas formas de rugosidades, e aponta a sua inércia dinâmica sobre os processos sociais posteriores. Por inércia dinâmica, entende uma sobre determinação do espaço na vida econômica. As construções antigas tornam-se qualidade do 
lugar. A partir daí estabelece a possibilidade de uma Geografia como "história territorial". (MORAES; COSTA, 1984, p, 125).

O valor no espaço é definido por Moraes e Costa (1984, p. 130-131) como "a própria espacialidade contida nos modos de produção. Ele nos revela mais a especificidade das formas de valorização em geral do que propriamente a da produção do espaço".

Diferenciar o valor do espaço e valor no espaço é importante como recurso analítico a sua unidade no processo de valorização. Ao entender a relação sociedade-espaço como um processo de valorização, cujo movimento interno deve ser em sua essência um processo de criação de valores com caráter próprio, embora, em nenhum momento, deixa de ser um processo universal que externaliza as determinações de um modo de produção, o espaço como objeto de valorização não se confunde com outros objetos de valorização material imediata, visto que ele não é apenas um produto, mas uma condição à produção e à existência humana. (MORAES; COSTA, 1984).

Neste contexto, acredita-se que se deve pensar o espaço em sua complexidade e simultaneidade, ou seja, um mundo globalizado que apresenta uma multiplicidade de fenômenos que ocupam uma mesma espacialidade, criando formas contraditórias e desiguais, no tempo e no espaço, marcadas por relações de poder decorrentes do sistema de desenvolvimento a qual estão inseridas, e que contribuem para a reprodução e continuidade da sociedade.

\section{PAISAGEM E AS RUGOSIDADES}

O estudo da paisagem é fundamental na compreensão das rugosidades, uma vez que é na paisagem que a rugosidade se materializa, se torna visível, pois sua materialização remonta a tempos pretéritos.

Assim, para Santos (2014, p. 67-68) a paisagem é: “Tudo o que nós vemos, o que nossa visão alcança, é a paisagem. Esta pode ser definida como o domínio do visível, aquilo que a vista abarca. É formada não apenas de volumes, mas também de cores, movimentos, odores, sons etc.”

Seguindo as ideias de Santos (2014) a paisagem é um conjunto heterogêneo de formas naturais e artificiais, formada por frações de ambas seja ao tamanho, volume, cor, utilidade ou por qualquer outro critério. Portanto, a paisagem é sempre heterogênea.

A paisagem não se forma de uma só vez, mas por acréscimos, por substituições, seguindo a mesma lógica de criação de um objeto no passado, o qual retrata a lógica de produção daquele momento. Assim, Santos (2014, p. 73) menciona que "a paisagem é uma escrita sobre a outra, é um conjunto de objetos que tem idades diferentes, é uma herança de muitos diferentes momentos".

A paisagem tem um movimento que pode ser mais ou menos rápido, à medida que as formas não se configuram apenas das possibilidades técnicas de uma época, mas dependem também 
das condições políticas, econômicas e culturais. A técnica assume um papel importante, mas não possui existência fora das relações sociais. Desta maneira, a paisagem deve ser pensada paralelamente as condições políticas, econômicas e culturais, pois as paisagens nos restituem todo um cabedal histórico de técnicas, mas não nos mostram todos os dados, os quais nem sempre são visíveis. (SANTOS, 2014).

Neste sentido, reporta-se a Souza $(2015$, p. 46) que enfatiza "a paisagem é a forma, uma aparência. O conteúdo "por trás" da paisagem pode estar em consonância ou em contradição com essa forma e com o que ela, por hábito ou ideologia, nos sugere". Assim, o fato de a paisagem ser uma forma, é conveniente interpretá-la ou compreendê-la a luz das relações entre forma e conteúdo, aparência e essência.

Para Souza (2015) a preocupação dos pesquisadores entre a essência e aparência da paisagem deve ser sanada através de entrevistas e questionamentos com a comunidade local bem como consulta a documentos diversos, evitando ao pesquisador apenas naturalizar relações sociais e econômicas que são contingentes, da forma criada, da paisagem incorporada no espaço, da rugosidade.

Nesse contexto, Luchiari (2001) considera que a paisagem é um vetor passivo, mas somada ao valor social que lhe é atribuído, transforma-se em espaço, processo ativo da dinâmica social. Tomada pelo indivíduo, a paisagem é forma e aparência, cujo verdadeiro conteúdo somente se revela por meio de funções sociais que lhes são constantemente atribuídas no desenrolar da história. Enfatiza que a paisagem é a materialidade, mas é ela que permite à sociedade a concretude de suas representações simbólicas, cujas práticas sociais podem produzir um novo contexto material que altera a forma/paisagem e introduz novos objetos, funções, valores e intencionalidades.

Nas análises de Berque (2004) a paisagem é uma marca, pois expressa uma civilização, mas é também uma matriz porque participa dos esquemas de percepção, de concepção e de ação ou seja, da cultura - que canalizam, em um certo sentido, a relação de uma sociedade com o espaço e com a natureza e, portanto, a paisagem do seu ecúmeno. Como marca, a paisagem pode e deve ser inventariada. Fazer o inventário das formas concretas da epiderme terrestre é a Geografia enquanto descrição da terra pelos geógrafos.

No espaço rural, as rugosidades expressam o trabalho presente na paisagem, denotando um passado/presente carregado de símbolos e significados, cuja identidade territorial configura relações de posse e pertencimento. A paisagem representa um documento-chave para entender as projeções socioculturais que representam ou se associam a um dado lugar. (DAVID, 2014).

A paisagem deve ser compreendida como uma concepção híbrida, carregada de natureza e cultura, de processos naturais e sociais, os quais mudam e continuam mudando com o decorrer dos tempos, cujo tempo apresenta diferentes formas de técnicas e trabalho, que associadas ao modo de 
desenvolvimento materializam rugosidades no espaço, criando uma paisagem única. Por isso, as rugosidades permitem apreciar e compreender a permanência de paisagens na contemporaneidade, cujos agenciamentos para tal configuração e conservação vão muito além dos agentes econômicos, pois representam não apenas a forma como se reproduzem, mas a forma como a sociedade vive e sua continuidade no tempo e no espaço, ou seja, a dialética espaço e sociedade.

\section{ANÁLISE E DISCUSSÃO DOS RESULTADOS}

As rugosidades do Sistema de Circulação de Mercadorias e Pessoas representam os meios de transporte, de comunicação e as infraestruturas criadas localmente para suprir as demandas advindas da implantação e fixação do homem no espaço. Foram inventariadas quatorze (14) rugosidades: Ponte de Pedra; Ponte do Passo Geral do Jacuí; Ponte Imperial; Viação Férrea (Estação de Ildefonso Fontoura, Estação de Ferreira, Estação de Pertile); Ponte Férrea; Porto de Cachoeira do Sul; Balsa São Lourenço; Balsa do Passo de Pertile; Ponte do Fandango; Posto de Combustível; Posto Telefônico e Agência Comunitária dos Correios (Figura 2).

Do total de 14 rugosidades inventariadas, 50\% foram criadas no século XIX e 50\% no século XX, 79 \% são de capital público e $21 \%$ de capital particular. Um terço, ou seja, 36\% das rugosidades perderam sua função e $64 \%$ continuam com sua função inicial de circulação.

Do montante das rugosidades, apenas duas rugosidades mantiveram sua forma sem passar por reformas, as quais perderam sua funcionalidade, e as demais passaram por algum tipo de reforma para manter e conservar sua estrutura e função. As mudanças da forma e função destas rugosidades atende a novos rearranjos do capital, que age de forma contraditória e desigual, para se ampliar e se reproduzir, ocasionando espaços de interesse como a circulação nas rodovias e espaços obsoletos como as estações férreas. 


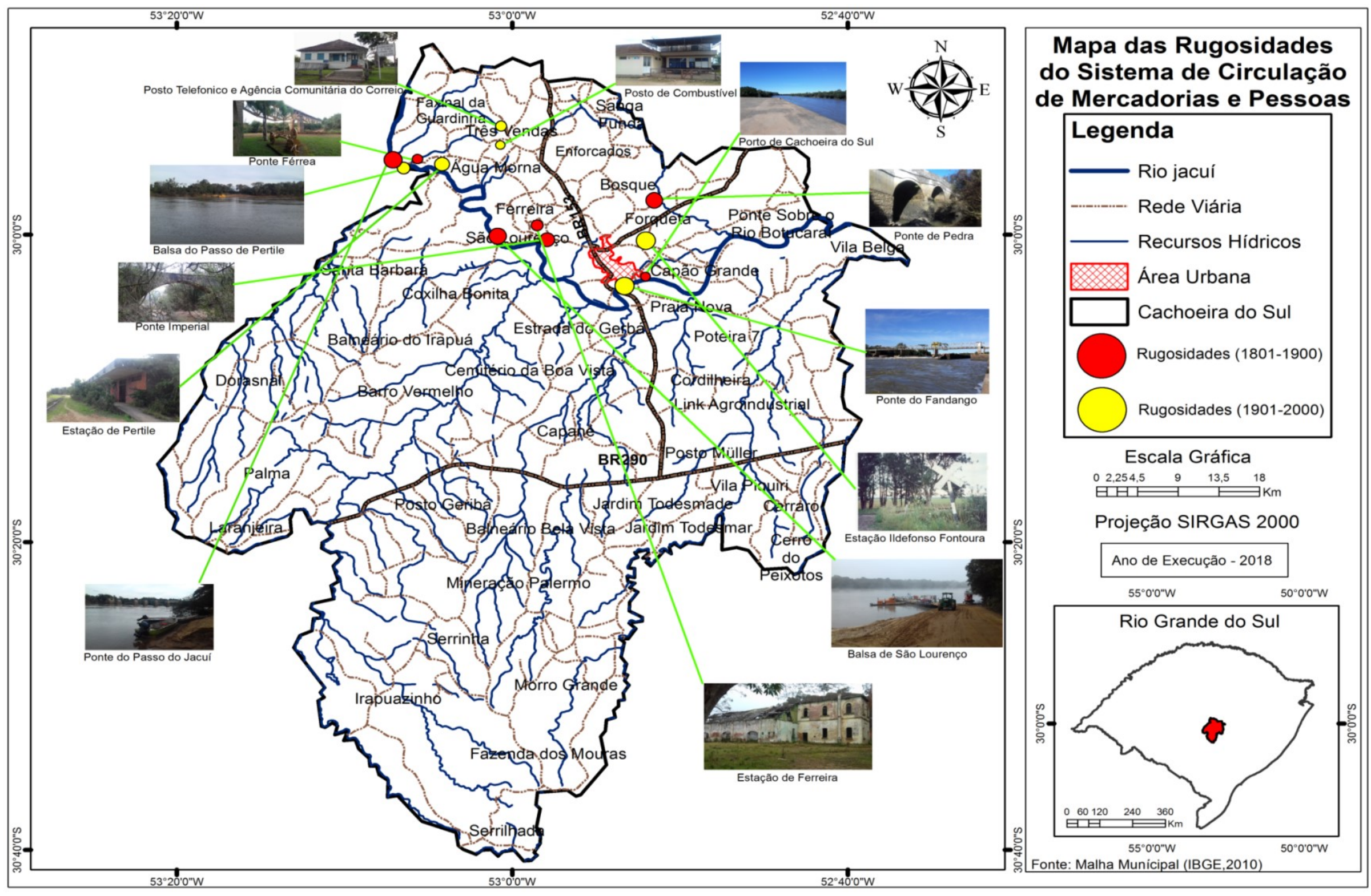

Figura 2 - Mapa das Rugosidades do Sistema de Circulação de Mercadorias e Pessoas da Paisagem Rural de Cachoeira do Sul, em 2018. Fonte: Trabalho de campo 2016-2018 
Todavia, mesmo esses espaços obsoletos são condição necessária à sua reprodução, pois dinamizam suas áreas de interesse. Compreender os agentes de criação e transformação do espaço através da constituição das rugosidades permite compreender as linhas de ação do capital e como o Estado atua para possibilitar a acumulação capitalista. Em se tratando, das vias de circulação, a logística de sua ação emana ações que priorizam as áreas de produção, consideradas áreas de interesse do capital. Portanto, as rugosidades do Sistema de Circulação de Mercadorias e de Pessoas são o resultado das demandas das formas de produção e reprodução da sociedade ao se perpetuar no espaço.

Entende-se que a revitalização e ressignificação dos meios de circulação de Cachoeira do Sul, deveria abranger um projeto integrado de desenvolvimento socioeconômico entre estado e município, detentores da maior parte das rugosidades deste sistema, que possibilitassem ações de ampliação da capacidade das estruturas presentes, bem como promovessem a reprodução social da população local.

Considera-se que a implantação de estradas parques poderia viabilizar o acesso entre as pontes, através da garantia de infraestrutura e sinalização incrementaria o desenvolvimento do turismo local, o que ainda poderia ser dinamizado por ações de implantação de comercialização de produtos rurais ao longo das estradas, garantindo a comercialização dos produtos dos pequenos agricultores familiares, incrementando e dinamizando suas fontes de renda.

Além disso, um projeto integrado turístico hidro-ferroviário com a implantação do trem turístico entre Cachoeira do Sul e Rio Pardo poderia representar ações de desenvolvimento às populações próximas as essas rugosidades, através da comercialização de produtos rurais nas estações, bem como a visitação das belezas naturais e artificiais, como as pontes no rio Jacuí, através de passeios guiados ao longo das rugosidades constituídas.

As rugosidades do Sistema de Produção compreendem dezesseis (16) rugosidades inventariadas: Estância da Capelinha; Fazenda São José - Tafona; Fazenda Borges de Medeiros; Estância do Lajeado; Estância São Gregório; Charqueada e Estabelecimento do Paredão; Granja Roesh; Engenho de Arroz Roesch; Engenho de Arroz Arno Ritzel; Engenho de Arroz Arlindo Dickow; Olaria Bortolatto \& Mello Ltda; Frigorífico Leusin; Venda e Banheiros de Imersão Bovinos (Figura 3).

Do total de 16 rugosidades inventariadas, 37,5\% foram criadas no século XIX e 62,5\% no século XX. A permanência das rugosidades do Sistema de Produção materializadas durante o século XIX deve-se ao fato de que elas representam a foram de reprodução predominante no parte sul do estado do Rio Grande do Sul. 


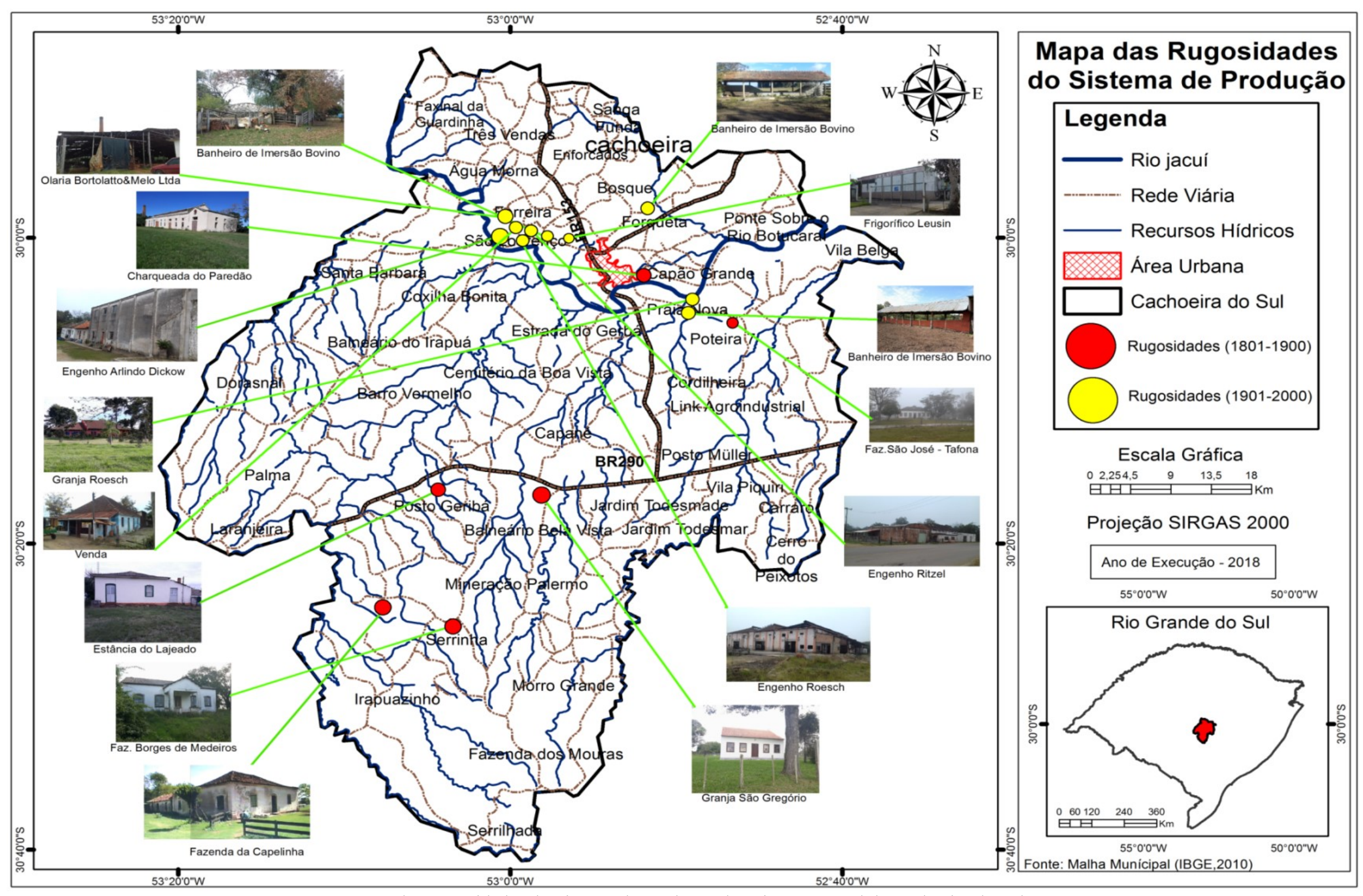

Figura 3 - Mapa das Rugosidades do Sistema de Produção da Paisagem Rural de Cachoeira do Sul, em 2018. Fonte: Trabalho de campo 2016-2018. 
Criadas a partir da implantação das sesmarias no território, passaram por várias divisões de área em função das sucessivas e numerosas divisões por herança, mas representam a continuidade da grande propriedade nesta espacialidade. Entretanto, sempre foram formas de reprodução que demandaram políticas públicas estatais de incentivo por parte do governo federal, ao passo que são responsáveis por produtos de exportação.

Neste contexto, é notório o predomínio de estâncias, fazendas e granjas na parte sul da espacialidade rural de Cachoeira do Sul como, por exemplo, Estância da Capelinha, Fazenda São José - Tafona, Estância do Lajeado, Fazenda Borges de Medeiros, Granja São Gregório e Granja Roesch, representando todas as rugosidades criadas no século XIX.

Em contrapartida, a maior parte das rugosidades do Sistema de Produção encontra-se localizadas na parte norte do município, cuja presença destas rugosidades corresponde a áreas propícias ao cultivo do arroz e proximidade com a área urbana municipal. Os banheiros de imersão estão presentes em todo o território municipal, mostrando que a preocupação com a qualidade sanitária era tanto das grandes propriedades, quanto das médias e pequenas.

Portanto, a localização de determinadas rugosidades em determinados lugares do município está relacionada com o tipo de ocupação e povoamento dessas áreas bem como o tipo de produção e o modelo dos sistemas produtivos introduzidos no meio rural.

Das rugosidades do Sistema de Produção apenas uma é de capital público (Charqueada do Paredão) representando 6,2\% e a demais são de capital privado, representando 93,8\% do total. Esse fato decorre que no modo de produção capitalista os meios de produção são privados e que as pertencentes ao Estado denotam interesse público, assim, como as rugosidades consideradas patrimônio cultural a serem preservadas.

As rugosidades do Sistema de Interação Social compreendem dezesseis (16) rugosidades inventariadas: as rugosidades casas antigas (casa antiga de Ferreira, casa antiga de Pertile e casa de antiga de Davi Fontoura de Barcellos); as rugosidades escolas (Escola Técnica Nossa Senhora da Conceição, Escola Municipal de Ensino Fundamental Jenny Figueiredo Vieira da Cunha, Escola Estadual de Ensino Fundamental Ernesto Pertile e Escola de Educação Infantil Sítio Encantado); as rugosidades igrejas (Igreja Capela Sagrada Família e Igreja Santo André); a rugosidade salão de baile (salão Boa Amizade); as rugosidades tapera, uma na localidade de Pertile, outra na localidade de Três Vendas e outra na localidade de Capané; e a rugosidade cemitérios familiares, dois no distrito de Bosque e um no distrito de Três Vendas (Figura 4). 


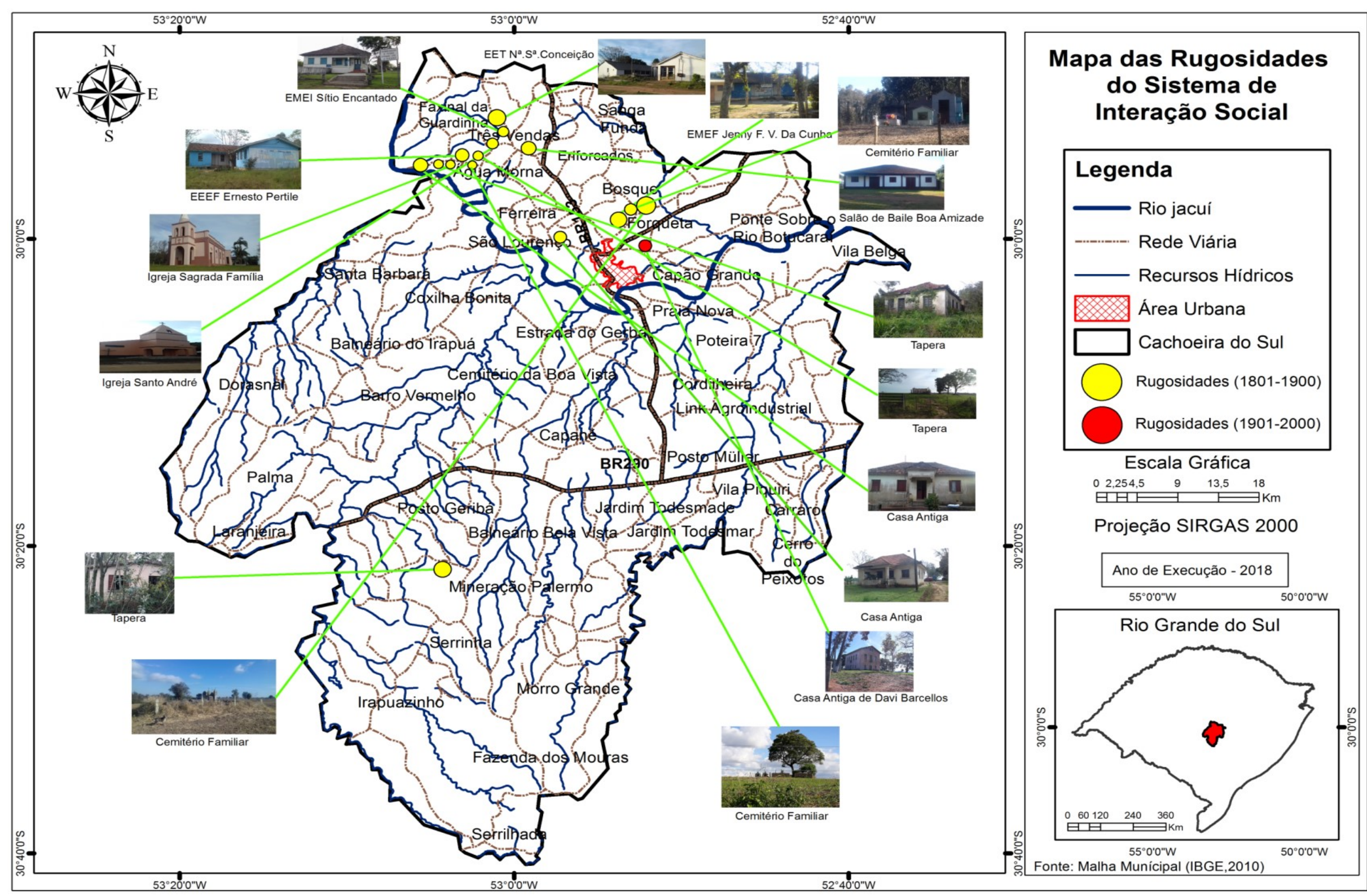

Figura 4 - Mapa das Rugosidades do Sistema de Interação Social da Paisagem Rural de Cachoeira do Sul, em 2018. Fonte: Trabalho de campo 2016-2018. 
A maioria das rugosidades foram criadas no século XIX, sendo que apenas a casa antiga que pertenceu a Davi de Fontoura Barcellos foi construída no século XIX. Observa-se também um predomínio da construção das rugosidades deste sistema em meados do século, cuja fixação e permanência do homem na espacialidade rural condicionam a construção de formas espaciais que possibilitam o homem estabelecer relações de sociabilidade.

As formas criadas na paisagem rural, as rugosidades pertencentes ao Sistema de Interação Social, se concentram na margem esquerda do rio Jacuí, na parte norte do município, sendo que apenas uma está localizada na parte sul do município, a Tapera localizada no distrito de Capané. O predomínio destas rugosidades na parte norte deve-se a estrutura agrária predominante, pois em áreas onde predomina a pequena propriedade as relações sociais são mais presentes, pois os homens encontram-se localizados mais próximos um dos outros, e, por conseguinte, as relações sociais também apresentam maior viabilidade de acontecer.

Em relação ao tipo de capital empregado, $75 \%$ são de propriedade privada e $25 \%$ são de propriedade pública. As rugosidades do Sistema de Interação Social representam as relações afetivas, religiosas e simbólicas dos grupos sociais. Elas denotam o modo de vida rural, que ao estabelecer inter-relações, cria marcas espaciais que se tornam heranças culturais dos grupos sociais.

As rugosidades do Sistema de Interação Social mostram o cotidiano da vida rural. Elas assumem valor no espaço à medida que representam o gênero de vida de um grupo social, o qual realiza atividades de convívio social e para isso cria marcas de representação simbólica que se perpetuam no tempo e no espaço.

\section{CONSIDERAÇÕES FINAIS}

As rugosidades são produzidas pela ação do homem ao longo dos tempos ao se reproduzir no espaço. Portanto, ao mesmo tempo em que o homem se reproduz ele cria espaço.

Ao analisar o contexto de criação e permanência das rugosidades na paisagem rural de Cachoeira do Sul, fica evidente que o fator econômico não é condição necessária para a produção da rugosidade. Ele é um condicionante a sua produção, pois a mudança no sistema produtivo não é condição preponderante à extinção da rugosidade, pois se o fator econômico fosse determinante nas relações de reprodução não existiriam rugosidades. Para a configuração de uma rugosidade é necessário uma complexidade de relações para viabilizar a materialidade da forma criada, esses rearranjos são determinados pelos agentes de transformação do espaço como o Estado, o capital e o pequeno capital, sendo o último representado pelo grupo social ali inserido. 
Os tempos de durabilidade e permanência das rugosidades no espaço rural são considerados maiores quando comparados com as rugosidades do espaço urbano. No rural as formas criadas não impedem o surgimento de novos sistemas de produção, pois existem áreas suficientes para a justaposição de sistemas produtivos com diferentes técnicas, relações de trabalho e tipos de capital. Já no espaço urbano, as áreas de especulação demandam notoriedade e disputas de poder.

Neste contexto, ressalta-se que as rugosidades criadas mais recentemente na paisagem rural municipal apresentam maior dinamismo e novas ressignificações, demandadas pelas novas necessidades da população rural ao se reproduzir. Assim, acredita-se que a comunidade cachoeirense precisa conhecer e reconhecer suas heranças espaciais, as rugosidades, mostrando as belezas e potencialidades das formas criadas pelos seus antepassados que em nada perdem para as criadas em outros municípios, países, etc., as quais devem ser difundidas em todo o território do Rio Grande do Sul, através de políticas municipais, dando visibilidade à riqueza das formas criadas e potencializando-as como fonte de desenvolvimento socioeconômico municipal.

As rugosidades devem ser entendidas como meios que possibilitam ressignificações e não como entraves ao desenvolvimento socioeconômico do lugar. A sua presença concreta valoriza o espaço e sua ressignificação possibilita aos grupos sociais do presente novas fontes de renda, de permanência no meio rural, contribuindo tanto para sua produção e reprodução como também para preservar do esquecimento e salvaguardar na memória as Rugosidades da Paisagem Rural de Cachoeira do Sul.

\section{REFERÊNCIAS}

BERQUE, A. Paisagem-Marca, Paisagem-Matriz: Elementos da Problemática para uma Geografia Cultural. In: CORRÊA, R. L.; ROSENDAHL, Z. Paisagem, tempo e cultura. Rio de Janeiro: EdUERJ, 2004.

CORRÊA, R. L. Região e Organização Espacial. 1. ed. São Paulo: Ática, 1986. 93p.

DAVID, C. “O campo se fez tapera...”: as paisagens do abandono no espaço rural sul-rio-grandense. In PIMENTA, M. de C. A.; FIGUEIREDO, L. C. Lugares: patrimônio, memória e paisagens. Florianópolis: Editora da UFSC, 2014.

LUCHIARI, M. T. D. P. A (re)significação da paisagem no período contemporâneo. In: CORREA R. L.; ROSENDAHL, Z. (Orgs.) Paisagem, Imaginário e espaço. Rio de Janeiro: EDUERJ, 2001.

MORAES, A. C. R.; COSTA, W. M. da. Geografia Crítica: A Valorização do Espaço. São Paulo: Hucitec, 1984. 196p.

SANTOS, M. A natureza do espaço: Técnica e Tempo, Razão e Emoção. 4. ed. São Paulo: Edusp, 2012. 392p. 
. Espaço e método. 5. ed. São Paulo: Edusp, 2014. 120p.

. Metamorfose do Espaço Habitado. 6. ed. São Paulo: Edusp, 2014. 136p.

. Por Uma Geografia Nova. 3. ed. São Paulo: Editora Hecitec, 1986. 288p.

. Por Uma Geografia Nova. 1. ed. São Paulo: Editora Hecitec, 1978. 288p.

SOUZA, M. L. de. Os conceitos fundamentais da pesquisa sócio-espacial. 2. ed. Rio de Janeiro: Bertrand Brasil, 2015. 320p. 